\title{
CANDIDATE GENES ASSOCIATED WITH POLYCYSTIC OVARY SYNDROME IN ASIAN POPULATIONS: A RESEARCH REVIEW
}

\author{
ABILASH VG* \\ Department of Biomedical Sciences, School of Bio Sciences and Technology, VIT University, Vellore - 632 014, Tamil Nadu, India. \\ Email: abilash.vg@vit.ac.in
}

Received: 21 April 2016, Revised and Accepted: 13 May 2016

\section{ABSTRACT}

Polycystic ovary syndrome (PCOS) is a complex genetic condition and is a highly prevalent heterogeneous syndrome of clinical and biochemical androgen excess. The disease has genetic as well as environmental involvements. The normal menstrual cycle results from a coordination of hormonal secretion and signaling within the hypothalamic pituitary-ovarian axis. Alterations in the normal cycle or irregularity in menstrual cycle result in amenorrhea, abnormal uterine bleeding, etc. The main causes are PCOS, hormonal imbalance, drugs, nutritional deficiency, personality, some genetic factors, and many more. Women with PCOS are often resistant to the biological effects of insulin and, as a consequence, may have high insulin levels. Women with PCOS are at risk for type 2 diabetes, high cholesterol, and high blood pressure. Obesity also appears to worsen the condition. The impact of the syndrome on an individual varies significantly based on several factors such as the severity of the components, comorbidities, and life course considerations. In addition, each individual experiences the syndrome in the context of her own reproductive health, metabolic, and quality-of-life concerns. Hirsutism, obesity, and infertility are common complaints. This review article gives a detailed account on the association of candidate genes associated with PCOS in South Asian population.

Keywords: Anti-mullerian hormone, Growth/differentiation factor 9, The bone morphogenetic protein, Follicle-stimulating hormone, Follistatin, Cytochrome p450, Polymerase chain reaction-restriction fragment length polymorphism.

(C) 2016 The Authors. Published by Innovare Academic Sciences Pvt Ltd. This is an open access article under the CC BY license (http://creativecommons. org/licenses/by/4. 0/) DOI: http://dx.doi.org/10.22159/ajpcr.2016.v9i5.12432

\section{INTRODUCTION}

Polycystic ovary syndrome (PCOS) is a complex genetic condition and is a highly prevalent heterogeneous syndrome of clinical and biochemical androgen excess. The disease has genetic as well as environmental involvements. The ovary is the central part for the pathogenesis of PCOS. Women affected by this disease show an increased prevalence of several comorbidities including obesity, dyslipidemia, hypertension, metabolism syndrome, and type 2 diabetes mellitus in comparison with women without PCOS. There has been evidence that shows both environmental as well as genetic factors [1-3]. In previous studies reported patients with masculine features, menstrual disturbance, and sclerocystic ovaries [4]. However, Stein and Leventhal were first to describe the traid of menstrual dysfunction, PCO and androgenic feature [5]. Treatment is focused on the goal of ameliorating hyperandrogenic symptoms including ovulation and preventing cardiometabolic complications. In genetic basis, the PCOS is an autosomal dominant trait. If analysis of affected families has noted that doubt about the mode of inheritance. Certain gene is responsible for the cause of PCOS. Involvement of several candidate genes has been proposed to contribute to susceptibility. Recent literature shows that up to 30\% of couples seeking treatment for PCOS [6]. As per 1990 National Institute of Health, 6-10\% of women are affected of PCOS in worldwide [7-11] and even more individuals according to broader Rotterdam criteria [12].

Candidate gene studies mainly focus on the relation between gene variations within pre-specified gene of interest and phenotype or disease state. The uses of candidate are explored potential causal pathways between genetic determinants and complex diseases, test whether a common genetic mechanism is associated with two or more traits that are believed to have similar biological pathways (e.g., major depression and schizophrenia). That contrast to genomewide association studies (GWAS), which scan the entire genome for common genetic variation. These genes can be identified by several methods including prior knowledge of the biological pathway; linkage studies, expression studies, and GWAS. Variants are selected based on the likelihood that they would produce a protein with altered function. The identification of single nucleotide polymorphisms (SNPs) within a gene can also be used to narrow the region of investigation. The study was done on population-based sample of cases and controls (affected and unaffected individuals). The candidate gene approach has already paid some dividends in trying to understand the complex genetics of PCOS. In terms of steroidogenic abnormalities, CYP11a-encoding P450 side chain cleavage appears to be a major susceptibility locus. In relation to the well-described metabolic disturbances in PCOS, the insulin gene variable number tandem repeat (VNTR) appears to be a promising candidate, at least in populations studied in the UK. Finally, genes implicated in ovarian follicular development may have a role in the etiology of PCOS as demonstrated by recent identification of the follistatin (FST) gene as a potential disease locus. It seems unlikely that PCOS can be explained on the basis of a single gene disorder although, in a given family, one gene may have a predominant effect. An oligogenic model seems the most appropriate basis on which to understand the genetic origins of this very common disorder. The candidate gene approach has been useful to date, but it may prove important in the near future to perform an anonymous genome-wide scan to identify hitherto unheralded susceptibility loci. The most common biochemical abnormality in women with PCOS is hyperandrogenemia. For this reason, researchers have long been trying to find a linkage or an association between PCOS and candidate genes so far studied by various research groups worldwide. This particular review article focus on the various candidates gene studied on Asian population based on polymerase chain reaction-restriction fragment length polymorphism (PCR-RFLP) method.

\section{CYP11A}

Cytochrome p450, subfamily xia, polypeptide 1 . The cholesterol side-chain cleavage enzyme (P450scc; EC 1.14.15.6), encoded by the CYP11A1 gene, initiates steroidogenesis by converting cholesterol to pregnenolone. P450scc catalyzes 3 consecutive reactions: 20-alphahydroxylation, 22-hydroxylation, and scission of the C20, 22 carbon bond [1]. There are a number of interlinking factors that affects 
expression of PCOS. The single cause of PCOS is unlikely. Other possible mechanisms in the pathogenesis of PCOS are discussed [2]. The sixrepeat allele is the most common fragment of (tttta) $\mathrm{n}$ microsatellite polymorphism in Chinese Han woman. The six-repeat allele variant may play a certain role in the pathogenesis of PCOS [3]. A disturbance of the hypothalamic-pituitary-gonadal axis, due to a reduction of hypothalamic and pituitary progesterone receptors might be a component in the etiology of PCOS [4]. Findings are consistent with the notion that there is an intrinsic alteration in the steroidogenic activity of PCOS theca cells that encompasses multiple steps in the biosynthetic pathway [5] said that the candidate gene approach has been useful to date, but it may prove important in the near future to perform an anonymous genomewide scan to identify hitherto unheralded susceptibility loci [6] Enhanced thecal androgen production is prenatally programmed in an ovine model of PCOS [7] said that PCOS is an oligogenic disorder in which a small number of key genes interact with environmental factors (notably dietary), the balance of which factors [8]. PCOS represents a complex trait in which several genes - but perhaps a relatively small number of key genes - contribute, in conjunction with nutritional factors, to the observed clinical and biochemical heterogeneity [9]. Studies indicate that the strength of, and indeed the existence of, associations between CYP11A promoter variation and androgen-related phenotypes has been substantially overestimated in previous studies. Several genes are linked to PCOS susceptibility. Because the mutations/ genotypes associated with PCOS are rare, and their full impact on the phenotype incompletely understood, routine screening of women with or stigmata of PCOS for these genetic variants is not indicated at this time. Currently, the treatment implications for individually identified genetic is uncertain and must be addressed on a case by case basis [10] Overexpression of CYP17 and CYP11A mRNA in theca cells from polycystic ovaries is explained by polymorphic differences in the gene promoters [11] said that in molecular genetic studies, that CYP11a, the gene coding for P450 side chain cleavage, is a key susceptibility locus for the development of hyperandrogenism [12]. Existing data suggest that it is probably involved in signal transduction mechanisms leading to altered expression of a suite of genes that affect theca cell steroidogenic activity as well as the metabolic phenotype of cell types including muscle and fat [13]. Although past genetic studies of PCOS have yielded only modest results, resources and techniques have been assembled to remedy the major deficits of these early studies, promising that the next few years will be a very exciting and rewarding era for the genetic analysis of PCOS [14] he molecular signature of PCOS theca cells defined by gene expression profiling [15]. PCOS represents a complex trait in which several genes but perhaps a relatively small number of key genes contribute, in conjunction with nutritional factors, to the observed clinical and biochemical heterogeneity [16]. The mutations/ genotypes associated with PCOS are rare, and their full impact on the phenotype incompletely understood, routine screening of women with or stigmata of PCOS for these genetic variants is not indicated at this time. Currently, the treatment implications for individually identified genetic is uncertain and must be addressed on a case by case [17]. The list of candidate genes studied in various Asian populations associated with PCOS is presented in Table 1.

\section{FST}

FST is an important regulator of activin and other members of the transforming growth factor-beta (TGF-beta) superfamily [18] but it will be absent in PCOS. The occurrence of the exonic variants of FST gene seems to be dependent on the ethnic background of the subjects under study and its role in the PCOS pathophysiology cannot be established with hitherto available evidence [19]. The epigenetic mechanisms involved in PCOS may yield new insights into the pathophysiology of the disorder [20]. Girls with premature pubarche (PP) could be considered a population at risk for plurimetabolic syndrome [21].

\section{FOLLICLE STIMULATING HORMONE BETA SUBUNIT (FSHB)}

Follicle-stimulating hormone enables ovarian folliculogenesis to the antral follicle stage. But in Pcos, it would be absent. The FSHB gene encodes the beta subunit of follicle-stimulating hormone. Anti-FSH may be naturally occurring antibodies associated with peripheral FSH concentrations, but increased in infertile women with dysregulation of immune reactions and repeatedly performed IVF [22]

\section{BONE MORPHOGENETIC PROTEIN 15 (BMP15) (GROWTH AND DIFFERENTIATION FACTORS [GDF]9B)}

The bone morphogenetic protein (BMP) family is part of the transforming growth factor-beta superfamily, which includes large families of GDF. These proteins are synthesized as prepropeptides, cleaved, and then processed into dimeric proteins. With few exceptions, members of the TGF-beta super family are defined by 7 spatially conserved cysteine residues these will be absent in PCOS. The mutational analysis of the coding region of BMP15 among 216 Chinese PCOS patients. Five novel missense mutations in BMP15 were discovered, namely, c.34C $>\mathrm{G}$, c. $109 \mathrm{G}>\mathrm{C}, \mathrm{c} .169 \mathrm{C}>\mathrm{G}, \mathrm{c} .288 \mathrm{G}>\mathrm{C}$, and c.598C $>$ T. These results are the first to indicate that BMP15 gene mutations may be potentially associated with PCOS patients [23].

\section{GDF9}

GDF9 - a member of the transforming growth factor-beta superfamily - is required for ovarian folliculogenesis. They analyzed ovaries from female mice deficient in GDF9 and demonstrated that primordial and primary 1-layer follicles could be formed, but there was a block in follicular development beyond the primary 1-layer follicle stage that led to complete infertility. Oocyte growth and zona pellucida formation proceeded normally, but other aspects of oocyte differentiation were compromised. Thus, the investigators concluded that GDF9 is the first oocyte-derived growth factor shown to be required for somatic cell function in vivo [24]. The mutations indicate GDF9 may be potentially associated with PCOS patents [25]. The expression of GDF9 and BMP15 in oocytes from patients, with which may be associated, with impaired oocyte quality and developmental competence in PCOS [26]. Single-cell expression analysis of BMP15 and GDF9 in mature oocytes and BMPR2 in cumulus cells of women with PCOS undergoing controlled ovarian hyperstimulation [27].

\section{ANTI-MULLERIAN HORMONE (AMH)}

Male sex differentiation is mediated by 2 discrete hormones produced by the fetal testis. Testosterone, produced by Leydig cells, virilizes the external genitalia and promotes prostatic growth; $\mathrm{AMH}$, also called mullerian-inhibiting substance or factor, results in regression of mullerian ducts which would otherwise differentiate into the uterus and fallopian tubes. FSH may inhibit the excessive secretion of AMH by suppressing the luciferase activity of $\mathrm{AMH}$ promoter, but it has no effect on AMHRII expression [28] FSH may inhibit the excessive secretion of AMH and stimulate follicle growth in PCOS granulosa cells by suppressing activity and expression of promoter [29] There is no evidence that follicle-stimulating hormone receptor p.Asn680Ser genotypes are associated with PCOS, high AMH levels or response to clomiphene citrate [30] individual TagSNPs in AMH gene do not affect susceptibility to PCOS, haplotypes of the two SNPs were associated with PCOS risk, as TA haplotype might enhance susceptibility to PCOS and GA inversely [31].

\section{LEPTIN RECEPTOR (LEPR)}

Leptin, an adipocyte-specific hormone that regulates adipose-tissue mass through hypothalamic effects on satiety and energy expenditure, acts through the LEPR, a single-transmembrane-domain receptor of the cytokine receptor family. Genotype combination and haplotype analyses indicate that Gln223Arg and Pro 1019Pro polymorphisms of LEPR are significantly associated with the risk of PCOS [32].

\section{INSULIN RECEPTOR SUBSTRATE-1 (IRS1)}

IRS1 found that IRS1 exhibited no intrinsic enzyme activity [33]. They suggested that it serves as a docking protein involved in binding and 
Table 1: List of candidate Genes studied in various Asian populations associated with PCOS

\begin{tabular}{|c|c|c|c|c|c|c|c|}
\hline \multirow[t]{2}{*}{ Serial number } & \multirow[t]{2}{*}{ Gene } & \multirow[t]{2}{*}{ Number of article } & \multicolumn{2}{|l|}{ Number of sample } & \multirow[t]{2}{*}{ Method } & \multirow[t]{2}{*}{ Year } & \multirow[t]{2}{*}{ Author name } \\
\hline & & & Control & Patient & & & \\
\hline 1 & FSHB & 1 & 105 & 135 & PCR-RFLP & 2007 & Haller et al. \\
\hline \multirow{2}{*}{2} & & 2 & 3 & 38 & PCR-RFLP & 2010 & Wang et al. \\
\hline & & 3 & 35 & 18 & PCR-RFLP & 2012 & de Resende et al. \\
\hline 3 & BMP15 (GDF9B) & 1 & 3 & 35 & PCR-RFLP & 2011 & Liu et al. \\
\hline \multirow[t]{4}{*}{4} & IRS1 & 1 & 30 & 30 & PCR-RFLP & 2014 & Chen et al. \\
\hline & & 2 & 60 & 60 & PCR-RFLP & 2012 & Ruan et al. \\
\hline & & 3 & 175 & 150 & PCR-RFLP & 2013 & Skrgatić et al. \\
\hline & & 4 & 88 & 183 & PCR-RFLP & 2010 & Christopoulos et al. \\
\hline \multirow[t]{4}{*}{5} & $\mathrm{AMH}$ & 1 & 20 & 43 & PCR-RFLP & 2012 & Li et al. \\
\hline & & 2 & 20 & 43 & PCR-RFLP & 2011 & Li et al. \\
\hline & & 3 & 512 & 475 & PCR-RFLP & 2013 & Xu et al. \\
\hline & & 4 & 80 & 54 & PCR-RFLP & 2012 & Mohiyiddeen et al. \\
\hline 6 & LEPR & 1 & 58 & 56 & PCR-RFLP & 2013 & Li et al. \\
\hline \multirow[t]{15}{*}{7} & CYP11A & 1 & 20 multiplex families & & PCR-RFLP & 2005 & Wood et al. \\
\hline & & 3 & 20 multiplex families & & PCR-RFLP & 2000 & Hogg et al. \\
\hline & & 4 & 20 multiplex families & & PCR-RFLP & 1999 & Franks et al. \\
\hline & & 5 & 20 multiplex families & & PCR-RFLP & 2001 & Franks et al. \\
\hline & & 6 & 20 multiplex families & & PCR-RFLP & 2012 & Legro et al. \\
\hline & & 7 & 20 multiplex families & & PCR-RFLP & 1999 & Meyer et al. \\
\hline & & 8 & 20 multiplex families & & PCR-RFLP & 1998 & Wang et al. \\
\hline & & 9 & 20 multiplex families & & PCR-RFLP & 2004 & Urbanek \\
\hline & & 10 & 24 & 12 & PCR-RFLP & 2001 & Gaasenbeek et al. \\
\hline & & 11 & 20 multiplex families & & PCR-RFLP & 2002 & Daneshmand et al. \\
\hline & & 12 & 20 multiplex families & & PCR-RFLP & 2002 & Jakimiuk et al. \\
\hline & & 13 & 20 multiplex families & & PCR-RFLP & 1999 & Franks et al. \\
\hline & & 14 & 20 multiplex families & & PCR-RFLP & 2003 & Franks et al. \\
\hline & & 15 & 20 multiplex families & & PCR-RFLP & 2007 & Franks et al. \\
\hline & & 16 & 20 multiplex families & & PCR-RFLP & 2004 & Strauss et al. \\
\hline \multirow[t]{3}{*}{8} & FST & 1 & 107 & 173 & PCR-RFLP & 2007 & Sang et al. \\
\hline & & 2 & 120 & 130 & PCR-RFLP & 2013 & Teixeira et al. \\
\hline & & 3 & 14 & 25 & PCR-RFLP & 2004 & Dasgupta et al. \\
\hline
\end{tabular}

PCR-RFLP: Polymerase chain reaction-restriction fragment length polymorphism, FSHB: Follicle stimulating hormone beta subunit, GDF: Growth and differentiation factors, IRS1: Insulin receptor substrate-1, BMP: Bone morphogenetic protein, AMH: Anti-mullerian hormone, LEPR: Leptin receptor, FST: Follistatin

activating other signal transduction molecules after being phosphorylated on tyrosine by insulin receptor kinase. This protein, designated IRS1, was found in a variety of insulin-responsive cells and tissues. The IRS-1 polymorphism is associated with increased susceptibility to PCOC in Greek population [34] meta-analysis suggested that IRS-1 Gly972Arg polymorphism might be considered a significant risk for PCOS. No significant associations were observed in IRS-2 Gly1057Asp polymorphism [35]. According to data does not support an association between VNTR INS, C/T [36]. According to earlier report there is no significant differences were observed in the genotype and allele distribution of the VNTR INS, C/T INSR, Gly792Arg IRS-1 polymorphisms between cases and controls. Moreover, no association was found between VNTR INS, C/T INSR and Gly792Arg IRS-1 polymorphism and parameters of insulin resistance in PCOS patients [36].

\section{CONCLUSION}

The involvement of candidates genes in the PCOS has been compared in the South Asian population. Previous research finding suggests that genetic and some environmental factors are responsible for PCOS. Through the efforts of researches, it is possible to find relation between candidate gene and PCOS. Using this knowledge background, will be able to identify the candidate gene is more responsible for the PCOS and help for treatment. Much works are still to be completed to fully determine the correlation between candidate gene and PCOS.

\section{ACKNOWLEDGMENT}

The authors would like to express their gratitude to VIT University authorities for providing all the facilities needed for the successful completion of this project.

\section{REFERENCES}

1. Sahakitrungruang T, Tee MK, Blackett PR, Miller WL. Partial defect in the cholesterol side-chain cleavage enzyme P450scc (CYP11A1) resembling nonclassic congenital lipoid adrenal hyperplasia. J Clin Endocrinol Metab 2011;96(3):792-8.

2. Jakubowski L. Genetic aspects of polycystic ovary syndrome. Endokrynol Pol 2005;56(3):285-93.

3. Wang Y, Wu XK, Cao YX, Yi L, Zou Y, Qu JW, et al. Microsatellite polymorphism of (tttta) $\mathrm{n}$ in the promoter of CYP11a gene in Chinese women with polycystic ovary syndrome. Zhonghua Yi Xue Za Zhi 2005;85(48):3396-400.

4. Meyer MF, Gerresheim F, Pfeiffer A, Epplen JT, Schatz H. Association of polycystic ovary syndrome with an interstitial deletion of the long arm of chromosome 11. Exp Clin Endocrinol Diabetes 2000;108(8):519-23.

5. Nelson VL, Legro RS, Strauss JF $3^{\text {rd }}$, McAllister JM. Augmented androgen production is a stable steroidogenic phenotype of propagated theca cells from polycystic ovaries. Mol Endocrinol 1999;13(6):946-57.

6. Franks S, Gharani N, McCarthy M. Candidate genes in polycystic ovary syndrome. Hum Reprod Update 2001;7(4):405-10.

7. Hogg K, Young JM, Oliver EM, Souza CJ, McNeilly AS, Duncan WC Enhanced thecal androgen production is prenatally programmed in an ovine model of polycystic ovary syndrome. Endocrinology 2012;153(1):450-61.

8. Franks S, Gharani N, McCarthy M. Genetic abnormalities in polycystic ovary syndrome. Ann Endocrinol (Paris) 1999;60(2):131-3.

9. Gaasenbeek M, Powell BL, Sovio U, Haddad L, Gharani N, Bennett A, et al. Large-scale analysis of the relationship between CYP11 A promoter variation, polycystic ovarian syndrome, and serum testosterone. J Clin Endocrinol Metab 2004;89(5):2408-13.

10. Jakimiuk AJ, Weitsman SR, Navab A, Magoffin DA. Luteinizing hormone receptor, steroidogenesis acute regulatory protein, and steroidogenic enzyme messenger ribonucleic acids are overexpressed in thecal and granulosa cells from polycystic ovaries. J Clin Endocrinol 
Metab 2001;86(3):1318-23.

11. Daneshmand S, Weitsman SR, Navab A, Jakimiuk AJ, Magoffin DA. Overexpression of theca-cell messenger RNA in polycystic ovary syndrome does not correlate with polymorphisms in the cholestero side-chain cleavage and 17alpha-hydroxylase/C(17-20) lyase promoters. Fertil Steril 2002;77(2):274-80.

12. Franks S, Gharani N, Gilling-Smith C. Polycystic ovary syndrome: Evidence for a primary disorder of ovarian steroidogenesis. J Steroid Biochem Mol Biol 1999;69(1-6):269-72.

13. Strauss JF $3^{\text {rd }}$. Some new thoughts on the pathophysiology and genetics of polycystic ovary syndrome. Ann N Y Acad Sci 2003;997:42-8.

14. Urbanek M. The genetics of the polycystic ovary syndrome. Nat Clin Pract Endocrinol Metab 2007;3(2):103-11.

15. Wood JR, Ho CK, Nelson-Degrave VL, McAllister JM, Strauss JF $3^{\text {rd }}$. The molecular signature of polycystic ovary syndrome (PCOS) theca cells defined by gene expression profiling. J Reprod Immunol 2004;63(1):51-60.

16. Franks S, Gharani N, Waterworth D, Batty S, White D, Williamson R, et al. Genetics of polycystic ovary syndrome. Mol Cell Endocrinol 1998;145(1-2):123-8.

17. Legro RS, Strauss JF. Molecular progress in infertility: Polycystic ovary syndrome. Fertil Steril 2002;78(3):569-76.

18. Schneyer AL, Wang Q, Sidis Y, Sluss PM. Differential distribution of follistatin isoforms: Application of a new FS315-specific immunoassay. J Clin Endocrinol Metab 2004;89(10):5067-75.

19. Dasgupta S, Pisapati SV, Kudugunti N, Kathragadda A, Godi S, Reddy MB. Does follistatin gene have any direct role in the manifestation of polycystic ovary syndrome in Indian women? J Postgrad Med 2012;58(3):190-3.

20. Sang Q, Zhang S, Zou S, Wang H, Feng R, Li Q, et al. Quantitative analysis of follistatin (FST) promoter methylation in peripheral blood of patients with polycystic ovary syndrome. Reprod Biomed Online 2013;26(2):157-63.

21. Teixeira RJ, Ginzbarg D, Rodrigues Freitas J, Fucks G, Silva CM, Bordallo MA. Serum leptin levels in premature pubarche and prepubertal girls with and without obesity. J Pediatr Endocrinol Metab 2004;17(10):1393-8.

22. Haller K, Salumets A, Grigorova M, Talja I, Salur L, Béné MC, et al. Putative predictors of antibodies against follicle-stimulating hormone in female infertility: A study based on in vitro fertilization patients. Am J Reprod Immunol 2007;57(3):193-200.

23. Liu J, Wang B, Wei Z, Zhou P, Zu Y, Zhou S, et al. Mutational analysis of human bone morphogenetic protein 15 in Chinese women with polycystic ovary syndrome. Metabolism 2011;60(11):1511-4.

24. Dong J, Albertini DF, Nishimori K, Kumar TR, Lu N, Matzuk MM. Growth differentiation factor-9 is required during early ovarian folliculogenesis. Nature 1996;383(6600):531-5.
25. Wang B, Zhou S, Wang J, Liu J, Ni F, Yan J, et al. Identification of novel missense mutations of GDF9 in Chinese women with polycystic ovary syndrome. Reprod Biomed Online 2010;21(3):344-8.

26. Wei LN, Liang XY, Fang C, Zhang MF. Abnormal expression of growth differentiation factor 9 and bone morphogenetic protein 15 in stimulated oocytes during maturation from women with polycystic ovary syndrome. Fertil Steril 2011;96(2):464-8.

27. de Resende LO, Vireque AA, Santana LF, Moreno DA, de Sá Rosa e Silva AC, Ferriani RA, et al. Single-cell expression analysis of BMP15 and GDF9 in mature oocytes and BMPR2 in cumulus cells of women with polycystic ovary syndrome undergoing controlled ovarian hyperstimulation. J Assist Reprod Genet 2012;29(10):1057-65.

28. Li Y, Wei LN, Liang XY. Follicle-stimulating hormone suppressed excessive production of antimullerian hormone caused by abnormally enhanced promoter activity in polycystic ovary syndrome granulosa cells. Fertil Steril 2011;95(7):2354-8, 2358.e1.

29. Li Y, Liang XY. Effect of follicle stimulating hormone on the secretion of anti-mullerian hormone in the granulosa cells in patients with polycystic ovarian syndrome. Zhonghua fu chan ke za zhi 2012;47(1):5-8.

30. Mohiyiddeen L, Salim S, Mulugeta B, McBurney H, Newman WG Pemberton $\mathrm{P}$, et al. PCOS and peripheral AMH levels in relation to FSH receptor gene single nucleotide polymorphisms. Gynecol Endocrinol 2012;28(5):375-7.

31. Xu P, Shen SM, Zhang XL, Liang F, Xie GB, Yi L, et al. Haplotype analysis of single nucleotide polymorphisms in anti-Müllerian hormone gene in Chinese PCOS women. Arch Gynecol Obstet 2013;288(1):125-30.

32. Li L, Lee KJ, Choi BC, Baek KH. Relationship between leptin receptor and polycystic ovary syndrome. Gene 2013;527(1):71-4.

33. Sun XJ, Rothenberg P, Kahn CR, Backer JM, Araki E, Wilden PA, et al Structure of the insulin receptor substrate IRS-1 defines a unique signal transduction protein. Nature 1991;352(6330):73-7.

34. Christopoulos P, Mastorakos G, Gazouli M, Deligeoroglou E, Katsikis I, Diamanti-Kandarakis E, et al. Study of association of IRS-1 and IRS-2 genes polymorphisms with clinical and metabolic features in women with polycystic ovary syndrome. Is there an impact? Gynecol Endocrinol 2010;26(9):698-703.

35. Ruan Y, Ma J, Xie X. Association of IRS-1 and IRS-2 genes polymorphisms with polycystic ovary syndrome: A meta-analysis. Endocr J 2012;59(7):601-9.

36. Skrgatic L, Baldani DP, Gersak K, Cerne JZ, Ferk P, Coric M. Genetic polymorphisms of INS, INSR and IRS-1 genes are not associated with polycystic ovary syndrome in Croatian women. Coll Antropol 2013;37(1):141-6

37. Chen L, Xu WM, Zhang D. Association of abdominal obesity, insulin resistance, and oxidative stress in adipose tissue in women with polycystic ovary syndrome. Fertil Steril 2014;102(4):1167-1174.e4. 